\title{
O estágio nos cursos de licenciatura em matemática em universidades baianas: recontextualizações e (re)existências
}

\author{
Mayara de Miranda Santos \\ Flávia Cristina de Macêdo Santana \\ Marta Élid Amorim
}

\begin{abstract}
Resumo: Este artigo apresenta resultados de uma investigação que teve por objetivo analisar como foram recontextualizados os textos das Diretrizes Curriculares Nacionais (DCN) para os Projetos Pedagógicos dos Cursos (PPC) de Licenciatura em Matemática em universidades estaduais e federais do estado da Bahia. Nesta investigação, nosso foco recaiu sobre a proposta delineada para a oferta do componente curricular Estágio. Apoiamo-nos em uma abordagem qualitativa, operacionalizada por meio da análise documental. Os dados foram analisados e categorizados à luz do que propõe Basil Bernstein, considerando-se dois eixos: princípios norteadores das resoluções para a proposta de Estágio e princípios estratégicos das resoluções para a organização e operacionalização da proposta de Estágio. Os resultados apontam para convergências e divergências na operacionalização dos projetos, o que permite inferir que os textos encontrados nas DCN foram recontextualizados de forma seletiva nos PPC.
\end{abstract}

Palavras-chave: Diretrizes. Projetos Pedagógicos. Licenciatura em Matemática. Estágio Curricular Supervisionado. Recontextualização. Mestranda em Educação pela Universidade Estadual de Feira de Santana. Professora do Instituto Federal do Piauí (IFPI), campus de São Raimundo Nonato, Piauí, Brasil. iD https://orcid.org/0000-0002-6850-3881

$\square$ mayara.santos@ifpi.edu.br

Flávia Cristina de Macêdo Santana Doutor em Ensino, Filosofia e História das Ciências pela Universidade Federal da Bahia (UFBA). Professora da

Universidade Estadual de Feira de Santana, Feira de Santana, Bahia, Brasil.

(D) https://orcid.org/0000-0003-4685-

$\triangle$ fcmsantana

cmsantana@uefs.br

Marta Élid Amorim Doutora em Educação Matemática pela Universidade Anhanguera, de São Paulo.

Professora da Unversidade Federal de Sergipe, campus Itabaiana, Sergipe,

https://orcid.org/0000-0001-5909-

Recebido em 16/05/2021 Aceito em 30/06/2021

Publicado em 21/08/2021
Mayara de Miranda Santos

$\triangle$ martaelid@gmail.com

\section{The internship in the courses of graduation in mathematics in the universities baianas: recontextualizations and (re)stocks}

Abstract: This article presents the results of an investigation that aimed to analyze how the texts of the National Curriculum Guidelines (DCN) for Pedagogical Projects of mathematics Courses (PPC) of graduation in Mathematics in the state and federal universities in the state of Bahia were recontextualized. In this investigation, our focus was on the proposal outlined for the offer of the curricular component Internship. We rely on a qualitative approach, operationalized through documental analysis. The data were analyzed and categorized in the light of what Basil Bernstein proposes, considering two axes: guiding principles of resolutions for the proposed Internship and strategic principles of resolutions for the organization and operationalization of the Internship proposal. The results point to convergences and divergences in the operationalization of projects, which allows us to infer that the texts found in the NCDs were selectively recontextualized in the PPC.

Keywords: Guidelines. Pedagogical Projects. Graduation in Mathematics. Curricular Supervised Sternship. Recontextualization.

\section{Las prácticas en los cursos de grado en matemáticas en las universidades baianas: recontextualizaciones y (re) existencias}

Resumen: Este artículo presenta los resultados de una investigación que tuvo como objetivo analizar cómo se recontextualizaron los textos de las Directrices Curriculares Nacionales (DCN) para Proyectos Pedagógicos de Cursos de Licenciatura en Matemáticas (PPC) en universidades estatales y federales del estado de Bahía. En 
esta investigación, nuestro enfoque se centró en la propuesta esbozada para la oferta del componente curricular Pasantía. Nos apoyamos en un enfoque cualitativo, operacionalizado a través del análisis documental. Los datos fueron analizados y categorizados a la luz de lo que propone Basil Bernstein, considerándose dos ejes: principios rectores de las resoluciones para la propuesta Pasantía y principios estratégicos de las resoluciones para la organización y operacionalización de la propuesta de Pasantía. Los resultados apuntan a convergencias y divergencias en la operacionalización de los proyectos, lo que nos permite inferir que los textos encontrados en las ENT fueron recontextualizados selectivamente en el PPC.

Palabras clave: Directrices. Proyectos Pedagógicos. Licenciado en Matemáticas. Pasantía Curricular Supervisada. Recontextualización.

\section{Introdução}

No Brasil, a orientação de que o Estágio Curricular Supervisionado ${ }^{1}$ seja oferecido a partir do início da segunda metade do curso foi proposta a partir de 2002, quando o Conselho Nacional de Educação (CNE) instituiu as Diretrizes Curriculares Nacionais (DCN) para a Formação de Professores da Educação Básica em nível superior (BRASIL, 2002a; 2002b). Neste documento, foram delineadas 400 (quatrocentas) horas dedicadas ao estágio supervisionado, na área de formação e atuação na Educação Básica. Essa proposição foi enunciada, também, na Resolução CNE/CP 02/2015. Segundo o documento, o Estágio é compreendido como um "componente obrigatório da organização curricular das licenciaturas, sendo uma atividade específica, intrinsecamente articulada com a prática e com as demais atividades de trabalho acadêmico" (BRASIL, 2015).

Nessa direção, diferentes investigações têm tematizado o estágio não apenas como componente obrigatório do curso, mas como um campo propício para legitimar a articulação entre os conhecimentos teóricos e práticos nos diferentes tempos e espaços curriculares, bem como entre universidade e escola (PIMENTA; LIMA, 2017; 2019; RABELO; ABIB; AZEVEDO, 2021). Para Pimenta e Lima (2017), além dessas proposições, as ações e os registros reflexivos mostram o estágio como reflexão da práxis que se constitui como campo propício para o desenvolvimento do estágio com pesquisa e como pesquisa.

$\mathrm{Na}$ área de Educação Matemática, diferentes pesquisas têm argumentado que o estágio deve ser considerado como um momento de inserção do licenciando no campo de atuação, tornando-o objeto de pesquisa, estudo, análise e de interpretação crítica e embasando-se nas componentes curriculares do curso (TEIXEIRA; CYRINO, 2015; COSTA, SANTANA, LUNA, 2020; SILVA, OLIVEIRA, 2021; NEVES; FIORENTINI, 2021; BARBOSA; LOPES, 2021). Esses autores elencam potencialidades do estágio para a formação de professores de Matemática em diferentes contextos e práticas e

\footnotetext{
${ }_{1}$ Para evitar repetições, denominaremos o componente de Estágio Curricular Supervisionado apenas como Estágio, grafado com letra inicial em maiúsculo e o conceito estágio, grafado com letra inicial em minúscula.
} 
defendem a constituição de parcerias entre universidade e escolas, bem como a articulação entre formação inicial e continuada.

Entretanto, observamos que a maioria das investigações foi desenvolvida a partir da análise de dissertações e teses, ou associadas a pesquisas empíricas. Não há estudos que mostrem como a proposta de estágio presente nas DCN foi movida para os Projetos Pedagógicos dos Cursos de Licenciatura em Matemática (PPC). Esta lacuna nos motivou a buscar uma formulação teórica para analisar como são movidas as proposições sinalizadas nas diretrizes para os projetos de formação inicial de professores de Matemática em universidades estaduais e federais do estado da Bahia. Mais adiante, apresentaremos esse objetivo de maneira mais delimitada, com base na discussão teórica. Para tanto, mobilizaremos alguns conceitos da Teoria dos Códigos de Basil Bernstein (2000; 2003). Resumidamente, a teoria preocupa-se como poder e controle são traduzidos em princípios de comunicação pedagógica (BERNSTEIN, 2000; 2003). Para este artigo, nosso foco recai sobre as relações de poder, visto que há indícios dessas relações quando analisamos o que está posto nas DCN e o que é apresentado nos PPC.

Nas próximas seções, mobilizaremos conceitos da teoria de Bernstein (2003) como ferramenta teórico-metodológica para iluminar o fenômeno. Em seguida, apresentaremos as discussões e resultados das categorias elencadas, bem como as considerações finais.

\section{A recontextualização de textos a respeito do estágio das DCN para os PPC}

Inspirados em Bernstein (2000), consideramos que as DCN e cada PPC comunica algo a alguém, o que nos permitiu compreendê-los como um texto (BERNSTEIN, 2003). Para o autor, texto é qualquer representação pedagógica, seja ela falada, escrita, gestual, espacial, expresso na vestimenta, no currículo etc. Por exemplo, Rincón e Fiorentini (2016) analisaram vivências de estagiários ao desenvolverem atividades na Educação Básica e constataram que as experiências comunicaram práticas de ensinar e de aprender que se apresentaram nas relações observadas entre professores e alunos.

Com a promulgação das resoluções (BRASIL, 2002a; 2002b; 2015), os cursos de licenciatura foram requeridos a mover os textos a respeito do estágio das DCN para os PPC, ocorrendo uma forma de regulação para a circulação desses textos. Foram instituídas 400 horas na matriz curricular, dedicadas à realização do estágio, entretanto a forma como esse componente seria organizado, em termos de distribuição de carga horária e o que poderia ser abordado, ficou sob responsabilidade de cada curso. Ao considerar o deslocamento de textos dos documentos oficiais para os PPC, ocorreu um 
processo de recontextualização, visto que, ao serem discutidos, esses textos foram submetidos a uma transformação, de acordo com as relações comunicativas dos agentes de recontextualização, aqui compreendidos como os membros do Núcleo Docente Estruturante (NDE) ou do colegiado de um curso, responsáveis pela construção ou reformulação dos PPC. Nesse sentido, os textos enunciados nos documentos foram recontextualizados para os PPC de Licenciatura em Matemática. Podemos tomar como exemplo os estudos de Marinque (2009), os quais, mesmo não tomando esse referencial teórico como base, analisou doze projetos pedagógicos de cursos de licenciatura em Matemática do Brasil e observou o que e o como os textos da Resolução CNE/CP01/2002 foram recontextualizados e orientaram a organização da matriz curricular.

No processo de seleção dos textos, Bernstein (2000) identifica três campos: o campo de produção, o campo de recontextualização e o campo de reprodução. Os textos produzidos no campo de produção, antes de sua transmissão, passam por um processo de transformação nos campos recontextualizadores que, por sua vez, envolve a transformação do texto do campo de produção para o de reprodução. 0 autor difere dois tipos de campos recontextualizadores: o Campo de Recontextualização Oficial (CRO), criado e dominado pelo Estado e seus agentes, é o espaço onde se encontram os documentos oficiais, a exemplo das resoluções e o Campo de Recontextualização Pedagógica (CRP), e o espaço representado, nesta pesquisa, pelos cursos de licenciatura em matemática. Neste campo, os agentes recontextualizadores se reuniram para discutir e reformular os PPC para atender ao que está posto nos documentos oficiais. 0 terceiro, o campo de reprodução, é aquele no qual se localizam as instituições de educação básica, em que professores, muitas vezes, movem textos dos cursos de licenciatura, localizados no campo de recontextualização, para o contexto da sala de aula. Apesar de reconhecermos que esses campos não são totalmente independentes, neste estudo, focalizamos apenas nos PPC dos cursos de Licenciatura em Matemática, que é parte do CRP.

A recontextualização se refere ao movimento de textos em diferentes contextos de produção e reprodução, gerando novos sentidos para os discursos mediados pelas relações de poder e pela regulação de ordem social (BERNSTEIN, 2000). Para Lopes (2008), a recontextualização constitui-se uma transferência de textos de um contexto para outro, como, por exemplo, do contexto acadêmico para o contexto de um sistema educacional; do contexto de uma rede de ensino para o de uma escola. Ainda segundo a autora, na recontextualização, inicialmente, há uma descontextualização, em que textos são selecionados em detrimento de outros e são deslocados para questões, práticas e relações sociais distintas. Esse movimento pode se dar quando as instituições formadoras, aqui compreendidas como universidade e escola, trabalham de forma colaborativa, em prol da realização do estágio 
curricular supervisionado. Em contrapartida, os docentes em atuação na instituição escolar poderão participar de diferentes ações de formação continuada promovidas pela universidade, em consonância com o que propõe a Resolução CNE/CP 02/2015.

Segundo Bernstein (2000; 2003), quando um texto é deslocado de um contexto para outro por meio da recontextualização, ele se transforma em outro texto, não podendo mais ser identificado com aquele que foi recontextualizado. Logo, os textos que estão postos nos documentos oficiais para formação de professores não são iguais aos que estão postos nos projetos dos cursos, visto que eles foram apropriados e reposicionados de forma seletiva. Esta especificidade dos contextos pedagógicos é entendida, nos termos propostos por Bernstein (2000), como discurso pedagógico. Segundo o teórico, ele é "um princípio de recontextualização que seletivamente apropria, recoloca e relaciona outros discursos para constituir a sua própria ordem" (BERNSTEIN, 2000, p. 33). Assim, quando os textos das diretrizes são movidos para os PPC pelos agentes recontextualizadores, por exemplo, 0 discurso pedagógico age em termos da seleção, refocalização ou supressão sobre o que mover e como mover em termos dos princípios que operam a estruturação do projeto de curso. Inspirados em Bernstein (1996), entendemos princípios como um conjunto de regras subjacentes que configuram essa prática, os quais podem proporcionar e criar modelos capazes de gerar descrições específicas.

Nessa investigação, tomaremos como foco de análise o princípio de classificação (pode produzir variações entre forte ou fraco), que traduz as relações de poder para examinar as ligações entre 0 que está posto nas diretrizes e o que é recontextualizado para os PPC. De acordo com Bernstein (2000), as relações de poder estabelecem, legitimam e reproduzem fronteiras entre diferentes categorias, como por exemplo, entre os textos enunciados por médicos e pacientes, e entre os textos dos professores de Matemática e os dos acadêmicos. Desse modo, o poder tem ligação com o espaço no qual se delimitam essas fronteiras e coloca, no caso deste estudo, diretrizes e PPC em diferentes posições. Argumentamos que há hierarquia nas formas de comunicação, bem como na demarcação e nos critérios para a legitimação dos textos produzidos tanto no contexto de formulação de diretrizes que orientem a formação inicial de professores, como no contexto de reformulação de projetos de cursos para atender essas diretrizes.

Com nosso referencial teórico delimitado, agora reapresentamos nosso objetivo, que busca analisar como foram recontextualizados os textos das DCN para os PPC de licenciatura em Matemática em universidades estaduais e federais do estado da Bahia. Na seção seguinte, apresentaremos os caminhos percorridos para a realização desta pesquisa. 


\section{Método}

Esta pesquisa está vinculada a uma pesquisa mais ampla desenvolvida pelo Grupo de trabalho (GT) 07 - Formação de professores que ensinam Matemática da Sociedade Brasileira de Educação Matemática (SBEM). Para analisarmos como foram recontextualizados os textos das DCN para os PPC de licenciatura em Matemática em universidades estaduais e federais do estado da Bahia, apoiamonos em uma abordagem qualitativa (ADLER; ADLER, 1994). Essa abordagem consiste em práticas materiais e interpretativas que tornam o mundo visível, transformando-o em uma série de representações. A opção por esta abordagem tornou-se adequada pelo fato de o estudo qualitativo ser rico em dados descritivos, ter um plano aberto e flexível e focalizar a realidade de forma complexa e contextualizada (LÜDKE; ANDRÉ, 2005).

Considerando nosso objeto de estudo, esta investigação enquadra-se na modalidade de pesquisa documental. Segundo Lüdke e André (2005), a pesquisa documental pode constituir-se numa técnica valiosa na abordagem qualitativa. Para as autoras são considerados documentos quaisquer materiais escritos que possam ser usados como fonte de informação: leis e regulamentos, normas, pareceres, cartas, diários pessoais, jornais, arquivos escolares, etc. Neste trabalho, consideramos documentos as DCN e os PPC de Licenciatura em Matemática presenciais das universidades estaduais e federais do estado da Bahia. Segundo a Resolução CNE/CES 03/2003, o PPC é considerado, no âmbito do Sistema Nacional de Avaliação da Educação Superior, como instrumento de regulação dos cursos de graduação no país durante os processos avaliativos de: Autorização de Funcionamento, Reconhecimento do Curso e Renovação do Reconhecimento (BRASIL, 2003).

Como procedimento de coleta de dados, inicialmente consultamos o site do e-MEC para mapearmos as universidades baianas que ofertavam cursos de licenciatura em Matemática na modalidade presencial. Nesta busca, identificamos oito universidades de natureza administrativas diferentes, a saber: quatro universidades estaduais e quatro federais. Em seguida, acessamos os sites de cada instituição e realizamos o download dos PPC para a análise. Ao analisarmos as propostas, identificamos 17 cursos de Licenciatura em Matemática, em 17 campi de 8 universidades na Bahia², como podemos ver na tabela a seguir:

\footnotetext{
${ }^{2}$ Nesta análise não elencamos os institutos federais, localizados em Barreiras, Camaçari, Eunápolis, Salvador e Valença e que ofertam cursos de Licenciatura em Matemática.
} 
Tabela 1: informações gerais

\begin{tabular}{|c|c|c|c|c|c|}
\hline UNIVERSIDADE & MUNICÍPIO & $\begin{array}{c}\text { ANOS DE } \\
\text { IMPLEMENTAÇÃO/ } \\
\text { REFORMULAÇÃO }\end{array}$ & $\begin{array}{l}\text { PERIOODO } \\
\text { OFERTADO }\end{array}$ & $\begin{array}{l}\text { CARGA } \\
\text { HORÁRIA }\end{array}$ & $\begin{array}{l}\text { CARGA HORÁRIA DE } \\
\text { ESTÁGIO }\end{array}$ \\
\hline $\begin{array}{l}\text { Universidade do Estado da Bahia } \\
\text { (UNEB) }\end{array}$ & Alagoinhas & 1999/2011 & diurno & $3260 h$ & $405 \mathrm{~h}$ \\
\hline $\begin{array}{l}\text { Universidade do Estado da Bahia } \\
\text { (UNEB) }\end{array}$ & Barreiras & $2004 / 2011$ & diurno & $3260 \mathrm{~h}$ & $405 \mathrm{~h}$ \\
\hline $\begin{array}{l}\text { Universidade do Estado da Bahia } \\
\text { (UNEB) }\end{array}$ & Caetité & $2004 / 2010$ & noturno & $3260 h$ & $405 \mathrm{~h}$ \\
\hline $\begin{array}{l}\text { Universidade do Estado da Bahia } \\
\text { (UNEB) }\end{array}$ & Paulo Afonso & $2004 / 2012$ & noturno & $3260 \mathrm{~h}$ & $405 \mathrm{~h}$ \\
\hline $\begin{array}{l}\text { Universidade do Estado da Bahia } \\
\text { (UNEB) }\end{array}$ & Senhor do Bonfim & $2004 / 2011$ & noturno & $3260 \mathrm{~h}$ & $405 \mathrm{~h}$ \\
\hline $\begin{array}{l}\text { Universidade do Estado da Bahia } \\
\text { (UNEB) }\end{array}$ & $\begin{array}{l}\text { Teixeira de } \\
\text { Freitas }\end{array}$ & $2004 / 2012$ & $\begin{array}{l}\text { Diurno/ } \\
\text { noturno }\end{array}$ & $3260 h$ & $405 \mathrm{~h}$ \\
\hline $\begin{array}{l}\text { Universidade Estadual de Feira de } \\
\text { Santana (UEFS) }\end{array}$ & Feira de Santana & $1986 / 2019$ & diurno & $3380 \mathrm{~h}$ & $420 \mathrm{~h}$ \\
\hline $\begin{array}{l}\text { Universidade Estadual do } \\
\text { Sudoeste da Bahia (UESB) }\end{array}$ & Jequié & $2005 / 2011$ & $\begin{array}{l}\text { Diurno/ } \\
\text { noturno }\end{array}$ & $3260 \mathrm{~h}$ & $405 \mathrm{~h}$ \\
\hline $\begin{array}{l}\text { Universidade Estadual do } \\
\text { Sudoeste da Bahia (UESB) }\end{array}$ & $\begin{array}{l}\text { Vitória da } \\
\text { Conquista }\end{array}$ & $1999 / 2010$ & diurno & $3240 \mathrm{~h}$ & $495 h$ \\
\hline $\begin{array}{l}\text { Universidade Estadual de Santa } \\
\text { Cruz (UESC) }\end{array}$ & Ilhéus & $1999 / 2006$ & $\begin{array}{l}\text { Diurno/ } \\
\text { noturno }\end{array}$ & $3155 h$ & $405 \mathrm{~h}$ \\
\hline $\begin{array}{l}\text { Universidade Federal da Bahia } \\
\text { (UFBA) }\end{array}$ & Salvador & $1944 / 2009$ & diurno & $3192 h$ & $408 \mathrm{~h}$ \\
\hline $\begin{array}{l}\text { Universidade Federal da Bahia } \\
\text { (UFBA) }\end{array}$ & Salvador & $1944 / 2008$ & noturno & $3158 h$ & $408 \mathrm{~h}$ \\
\hline $\begin{array}{c}\text { Universidade Federal do } \\
\text { Recôncavo da Bahia (UFRB) }\end{array}$ & Amargosa & $2006 / 2018$ & diurno & $3338 \mathrm{~h}$ & $408 \mathrm{~h}$ \\
\hline $\begin{array}{l}\text { Universidade Federal do Oeste da } \\
\text { Bahia (UFOB) }\end{array}$ & Barreiras & $2009 / 2016$ & integral & $3280 \mathrm{~h}$ & $480 \mathrm{~h}$ \\
\hline $\begin{array}{l}\text { Universidade Federal do Sul da } \\
\text { Bahia (UFSB) } \\
\text { (Licenciatura interdisciplinar) }\end{array}$ & Itabuna & $2016 / 2016$ & $\begin{array}{l}\text { Vespertino/ } \\
\text { noturno }\end{array}$ & $3210 h$ & $400 \mathrm{~h}$ \\
\hline $\begin{array}{c}\text { Universidade Federal do Sul da } \\
\text { Bahia (UFSB) } \\
\text { (Licenciatura interdisciplinar) }\end{array}$ & Porto Seguro & $2016 / 2016$ & $\begin{array}{l}\text { Vespertino/ } \\
\text { noturno }\end{array}$ & $3210 h$ & $400 \mathrm{~h}$ \\
\hline $\begin{array}{l}\text { Universidade Federal do Sul da } \\
\text { Bahia (UFSB) } \\
\text { (Licenciatura interdisciplinar) }\end{array}$ & $\begin{array}{l}\text { Teixeira de } \\
\text { Freitas }\end{array}$ & $2016 / 2016$ & $\begin{array}{l}\text { Vespertino/ } \\
\text { noturno }\end{array}$ & $3210 \mathrm{~h}$ & $400 \mathrm{~h}$ \\
\hline
\end{tabular}

Fonte: Projetos Pedagógicos dos cursos (PPC) ${ }^{3}$

Passamos a analisar o movimento de recontextualização dos textos das DCN para os PCC a luz da linguagem de descrição proposta por Basil Bernstein. Essa linguagem possibilita construir uma

${ }^{3}$ A Universidade Federal do Sul da Bahia (UFSB) oferta o curso de Licenciatura interdisciplinar em Matemática e computação e suas tecnologias. Já a Universidade Estadual do Sudoeste da Bahia (UESB)/campus de Jequié oferta o curso de Licenciatura em Matemática com enfoque em informática. 


\section{revemop}

relação dialética entre os conceitos constituídos por uma teoria e os dados empíricos a serem analisados a partir de dois tipos de linguagem, a interna e a externa. A linguagem interna é constituída por uma teoria ou por um conjunto de teorias; e a linguagem externa é constituída por proposições e modelos derivados da linguagem interna de descrição (BERNSTEIN, 2000). Para este artigo, a seleção e a análise dos dados foram realizadas com base em um levantamento preliminar dos textos apresentados nas DCN e recontextualizados para os PPC. A segunda etapa correspondeu à codificação dos dados, seguidas pela interpretação e agrupamento em categorias. Por fim, confrontamos os resultados obtidos com a literatura, a fim de gerar compreensões teóricas e/ou confirmar/revisar aquelas já existentes.

\section{Discussão e Resultados}

Neste artigo, preocupamo-nos em analisar como foram recontextualizados os textos das DCN para os PPC de Licenciatura em Matemática em universidades estaduais e federais do estado da Bahia. Para tanto, consideramos duas categorias de análise: princípios norteadores das resoluções para a proposta de estágio e princípios estratégicos das resoluções para a organização e operacionalização da proposta de estágio. Essas categorias emergiram dos dados e foram sistematizados a partir de um diálogo com conceitos bernsteinianos apresentados anteriormente (BERNSTEIN, 2000, 2003).

\subsection{Princípios norteadores das resoluções para a proposta de Estágio}

Essa categoria coloca em tela reflexões epistemológicas a respeito dos textos das DCN que foram recontextualizados para os diferentes PPC e que passaram a nortear o desenvolvimento do estágio nos cursos de Licenciatura em Matemática. Compreendemos que o estágio consiste no momento de inserção do licenciando no campo de atuação, tomando-o em objeto de pesquisa, estudo, análise e interpretação crítica, fundamentando-se na articulação entre teoria e prática e nos diferentes componentes curriculares do curso (TEIXEIRA; CYRINO, 2015; PIMENTA; LIMA, 2017; 2019). O Estágio ganha legitimidade em torno de uma série de legislações que normatizam a obrigatoriedade para todos os cursos de licenciatura, a exemplo do que estabelecem as Resoluções CNE/CP 01/2002a, CNE/CP 02/2002b e CNE/CP 02/2015. Apesar das resoluções estabelecerem 400 horas da carga horária total do curso para a realização do Estágio, há diferenças de concepções nesses documentos, como apresentado a seguir: 
Art. $13 \S 3^{\circ} 0$ estágio curricular supervisionado, definido por lei, a ser realizado em escola de educação básica, e respeitado o regime de colaboração entre os sistemas de ensino, deve ser desenvolvido a partir do início da segunda metade do curso e ser avaliado conjuntamente pela escola formadora e a escola campo de estágio (BRASIL, 2002a, p. 6).

Observamos que no Art. $13 \S 3^{\circ}$ Resolução CNE/CP 01/2002a há um indicativo de que 0 Estágio deva ser realizado em regime de colaboração com a Escola da Educação Básica, mas essa proposição tem um teor burocrático e não evidencia a concepção de colaboração como um tipo de prática pedagógica ${ }^{4}$ em que todos(as) têm a função de ensinar e aprender, como apresentado em Santana e Barbosa (2018). Além disso, esse parágrafo atribui à escola a função de avaliar, mas no texto não está explícito quais parâmetros devem ser considerados para que isso ocorra, visto que a referida resolução tem a competência como concepção nuclear na orientação do curso. Inspirados em Bernstein (2003), argumentamos que a estruturação de um curso de Licenciatura em Matemática seguindo o modelo de ensino por competências, demarca relações de poder e induz a construção de currículos formatados para atender as avaliações nacionais, a exemplo do Exame Nacional de Desempenho de Estudantes (ENADE), realizado no contexto atual. Essa formação formatada evidencia uma forte classificação nos termos postos por Bernstein (2003).

O que difere da concepção apresentada na Resolução CNE/CP 02/2015, como apresentada a seguir:

Art. $13 \$ 6^{\circ} \mathrm{O}$ estágio curricular supervisionado é componente obrigatório da organização curricular das licenciaturas, sendo uma atividade específica intrinsicamente, articulada com a prática e com as demais atividades de trabalho acadêmico (BRASIL, 2015, p. 11).

O artigo supracitado estabelece a possibilidade de que aquilo tido como modelo de estágio seja historicamente ampliado e articulado com as demais atividades acadêmicas. Inspirados em Bernstein (2000), poderíamos dizer que nos deparamos com a necessidade de diminuir o distanciamento existente entre os diferentes componentes e contextos para contemplar ações associadas aos conhecimentos que futuros professores de Matemática necessitam para ensinar. Tal desafio convidanos a entender o processo de formação profissional subvertendo a proposta de formação formatada em um lastro de competências proposta na Resolução CNE/CP 02/2019. Precisamos refletir sobre as demandas advindas do cotidiano escolar e promover ações que articulem teoria e prática, universidade e escola, formação inicial e continuada. Essa proposição foi sinalizada no Parecer CNE/CP 02/2015, como podemos observar a seguir:

\footnotetext{
${ }^{4}$ Conforme Bernstein (2000), os reguladores das diversas modalidades da prática pedagógica são os princípios de classificação e enquadramento. Entendo prática pedagógica em termos bernsteinianos como um contexto social por meio do qual se realiza a produção e reprodução da cultura. Entre as práticas pedagógicas estão incluídas as relações entre arquiteto e engenheiro, médico e paciente, engenheiros e mestres de obra; no contexto escolar, essa prática envolve a relação entre professor e alunos.
} 
Ao mesmo tempo, os sistemas de ensino devem propiciar às instituições formadoras a abertura de suas escolas de educação básica para o estágio curricular supervisionado. Esta abertura, considerado o regime de colaboração prescrito no Art. 211 da Constituição Federal, pode se dar por meio de um acordo entre instituição formadora, órgão executivo do sistema e unidade escolar acolhedora da presença de estagiários. Em contrapartida, os docentes em atuação nesta escola poderão receber alguma modalidade de formação continuada a partir da instituição formadora. Assim, nada impede que, no seu projeto pedagógico, em elaboração ou em revisão, a própria unidade escolar possa combinar com uma instituição formadora uma participação de caráter recíproco no campo do estágio curricular supervisionado (BRASIL, 2015a, p. 31).

Observa-se que a articulação entre diferentes instituições pode contribuir para que textos sejam movidos de um contexto a outro com a finalidade de gerar um ambiente de investigação e propiciar o desenvolvimento de pesquisas no estágio e a respeito do estágio, como já sinalizado em diferentes pesquisas (PIMENTA; LIMA, 2017; COSTA; SANTANA; LUNA, 2020; NEVES; FIORENTINI, 2021). Encontramos nos PPC, textos que não fazem referência a essa parceria, mas a grande maioria legitima essa articulação por meio do estágio e projetos de extensão. Em termos bernsteinianos, essa proposição pode contribuir para diminuir o distanciamento existente entre universidade e escola, bem como entre formação inicial e continuada.

Ao analisarmos os PPC que compuseram o corpus dessa pesquisa, foi possível notar que alguns projetos reconhecem o texto das diretrizes e realizam propostas que contemplam estudos e investigações tomando como objeto o cotidiano da escola básica, a exemplo da UEFS, UFOB/Barreiras e UFRB/Amargosa, que até 2019, já tinham realizado as adequações atendendo a Resolução CNE/CP 02/2015. Entretanto, outros reconhecem, mas não produzem textos que legitimam as proposições sinalizadas nas diretrizes. Os modos como foram planejados e operacionalizados os processos formativos dos futuros professores nos PPC apresentam configurações e pressupostos que caracterizaram determinadas similitudes e diferenças, como é possível observar na imagem a seguir:

Figura 1: Aspectos das propostas

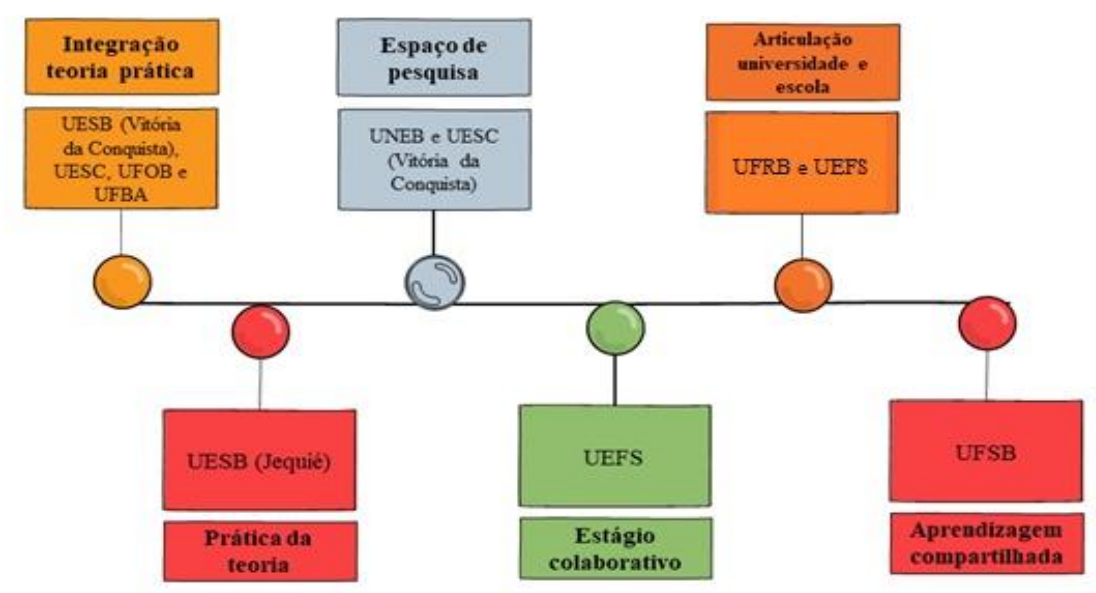

Fonte: Elaborado pelas autoras. 
A imagem nos mostra que os cursos da UESB (campus Vitória da Conquista), UESC, UFOB e UFBA concebem seus estágios como uma dimensão formativa que integra teoria e prática, em consonância com estudos que tematizam o estágio (TEIXEIRA; CYRINO, 2015; BARBOSA; LOPES, 2021). Nessa direção, Pimenta e Lima (2019) defendem que o estágio se constitua como eixo articulador dos projetos dos cursos, alinhando as disciplinas e as atividades tradicionalmente denominadas práticas e teóricas do currículo. As autoras defendem que esse processo formativo se constitua em uma atividade teórica de conhecimento da práxis de ensinar, em que se convergem os demais componentes teóricos do currículo. É uma configuração que pode favorecer uma formação que articule diferentes conhecimentos, que contemplem as diversas dimensões existentes nos processos de ensinar e de aprender.

Entretanto, o curso da UESB (campus Jequié) legitima a histórica concepção de estágio enquanto momento de colocar em prática o que se aprendeu na teoria, como é possível notar no excerto abaixo:

Especificamente no que se refere ao Estágio Supervisionado, ele será desenvolvido exclusivamente através de atividades práticas, individuais, em pequenos grupos e em grupos maiores, dependendo da atividade específica (UESB, 2011, p. 43).

Observa-se que esse trecho, característico do que defendia a Resolução CNE/CP 01/2002, entende o professor como um técnico prático, ficando a docência reduzida a habilidades instrumentais e práticas, sem teoria, nos temos postos por Pimenta e Lima (2019). Assim, nota-se que essa é uma concepção reducionista do estágio, visto que apresenta a hipótese de que aprender a ser professor ocorre pela imitação de práticas observadas, pressupondo que o ensino é uma atividade técnica, que após assimilada, pode ser aplicada em qualquer contexto. Inspirados em Bernstein (2000), argumentamos que essa compreensão instaura um maior distanciamento entre universidade e escola. Além disso, evidencia relações de poder à medida que elege o estágio como a hora da prática e compreende o currículo de forma fragmentada, composto por um leque de disciplinas de conhecimentos especializados que possuem fronteiras bem marcadas, impedindo a interlocução entre os conhecimentos acadêmicos, bem como a possibilidade de realização de um diálogo interdiciplinar. Para Bernstein (2003), o que temos é uma forte classificação.

O estágio configurado como espaço de pesquisa nos cursos de formação, além de contribuir para a construção da identidade docente, amplia e aprofunda o conhecimento pedagógico (TEIXEIRA; CYRINO, 2015; PIMENTA; LIMA, 2019). As autoras ainda afirmam que esse modelo de estágio contribui para formação de um profissional crítico-reflexivo e pesquisador de sua práxis e da práxis educativa que realiza na escola em que atua. Foi nessa direção que UNEB e UESB (campus Vitória da 
Conquista) operaram seus projetos, possibilitando ao licenciando refletir, investigar e agir sobre as representações que envolvam à docência, como podemos observar no trecho a seguir:

A observação e a regência proporcionam ao licenciando atitude reflexiva e investigativa que conduz informaç̃̃es para a complementação de pesquisas desenvolvidas ao longo do curso, que culminará na elaboração do Trabalho de Conclusão de Curso (UNEB, 2012, p.151).

Por meio da ação investigativa, é possível que o estagiário reflita sobre a realidade escolar, elabore propostas de intervenção e contribua com a melhora dos processos de ensino e de aprendizagem, além de aprender a docência na interação com os pares.

O curso da UEFS afirma ser esse um momento onde o licenciando terá efetiva participação nos processos de ensino e aprendizagem e que deverá contribuir para a realização de projetos coletivos dentro da escola básica. Essa visão de estágio colaborativo é defendida por Medeiros (2010) ao afirmar que 0 estágio quando ocorre de maneira colaborativa proporciona significados positivos aos sujeitos que se constituem professores. Os acadêmicos interagem com a realidade, refletem sobre as ações observadas e partilhadas no contexto escolar em que estão inseridos, criando suas próprias formas de ser e agir, como futuros professores.

Encontramos uma forte classificação na visão de estágio do curso da UFRB, que moveu de forma fiel os textos da Lei $n^{\circ}$ 11.788, de 25 de setembro de 2008 (Lei Federal de Estágio) para seu projeto, seguindo assim os princípios apresentados na referida lei. Entretanto, demarcamos a preocupação do colegiado desse curso e do curso da UEFS em fortalecerem suas relações institucionais com escolas da Educação Básica, convergindo com Pimenta e Lima (2019) que destacam que 0 exercício do estágio deve ser marcado pelo compromisso de integrar universidade e escola. Nessa direção, os sujeitos poderão se apoderar, de forma seletiva, dos diferentes discursos que permeiam os diferentes contextos de formação e, assim, constituir sua própria ordem, na perspectiva de Bernstein (2000).

No caso específico da UFSB, há uma particularidade, porque a proposta curricular é de licenciatura interdisciplinar e há um diálogo entre a Matemática e questões sociais. 0 estágio, neste curso, se dá de forma compartilhada e o estagiário conta com o apoio de outros estagiários em etapas formativas mais avançadas, configurando Equipes de Aprendizagem Ativa (EAA). Os projetos de intervenção pedagógica são elaborados de forma interdisciplinar dentro da grande área ou integrando diversas grandes áreas, após diálogo com as instituições formadoras. A concepção encontrada no curso da UFSB foi de aprendizagem compartilhada, um modelo que segundo Nörnberg e Cava (2015) permite alternância nos movimentos de poder relativos ao exercício da docência, desenvolve a 
corresponsabilidade e a colaboração ativa, pois no exercício de compartilhar, aprende-se a ser professor e se aprende a continuar sendo professor.

Tendo em vista as concepções encontradas e analisadas, apresentaremos, na próxima categoria, as formas como os cursos organizaram e operacionalizaram suas propostas de estágio.

\subsection{Princípios estratégicos para a organização e operacionalização da proposta de Estágio}

Nesta categoria, colocamos em evidencia alguns princípios estratégicos apresentados nos textos das diretrizes que foram recontextualizados para os diferentes PPC. Em 2002, com a promulgação as Resoluções CNE/CP 01/2002 e CNE/CP 02/2002 foram instituídas as DCN para formação de professores e estabeleceu a duração e carga horária para a realização dos cursos, respectivamente. Segundo a resolução, desse total $14,3 \%$ das 2800 h seriam destinados ao estágio, como podemos observar no Art. 1a seguir:

II - 400 (quatrocentas) horas de estágio curricular supervisionado a partir do início da segunda metade do curso (BRASIL, 2002a).

Na mesma direção, a Resolução CNE/CP 02/2015 em seu Art. $13^{\circ}$ instituiu:

II - 400 (quatrocentas) horas dedicadas ao estágio supervisionado, na área de formação e atuação na educação básica, contemplando também outras áreas específicas, se for o caso, conforme o projeto de curso da instituição (BRASIL, 2015).

O aumento da carga horária de estágio de 300 horas para 400 horas provocou movimentos de reformulações nos PPC de Licenciatura em Matemática desde a promulgação da Resolução CNE/CP 02/2002a e CNE/CP 02/2002b. O estágio ganhou uma nova configuração e deixou de ser ofertado apenas no final do curso. Entretanto, o modelo proposto tinha como foco o saber fazer, formatado por um leque de competências, como já citamos. Na Resolução CNE/CP 02/2015, apesar do aumento da carga horária total do curso passar para 3200h, não houve alteração na carga horária destinada ao estágio.

Observamos que embora os textos apresentados nos 17 PPC dos cursos de Licenciatura em Matemática ofertados na Bahia tenham atendido a normativa de no mínimo 400 horas de Estágio, instituições a exemplo da UFOB/Barreiras e a UESB/Vitória da Conquista chegaram a oferta 480h e 495h respectivamente, para o desenvolvimento de atividades relacionadas ao componente. Os estágios, nestas instituições contemplam estudos sistemáticos sobre a formação do professor que ensina Matemática no Ensino Fundamental e Médio. Além disso, nos primeiros componentes discutem 
sobre gestão, coordenação e supervisão e nos últimos colocam em debate questões relacionadas à Educação de Jovens e Adultos (EJA) e Ensino Técnico/Profissionalizante, como forma de viabilizar o atendimento às especificidades nas diferentes etapas e modalidades de educação básica, como previsto na Resolução CNE/CP 02/2015 (BRASIL, 2015). Tal Proposição foi também legitimada pelas estaduais UEFS, UESB (campus Vitória da Conquista) e as federais e pela UFBA e UFOB.

Quanto às condições de execução, UEFS, UFBA e UFOB demarcam a possibilidade de realização em espaços não escolares. Conforme Gabassa, Elias e Girotto (2017) a vivência de relações dialógicas articuladas aos conhecimentos de mundo e à realidade em que os espaços não escolares possibilitam, ampliam as possibilidades formativas para futuros professores. Outro ponto que consta nas diretrizes é a consolidação da educação inclusiva por meio do respeito às diferenças, reconhecendo e valorizando a diversidade étnico-racial, de gênero, sexual, religiosa, entre outras (BRASIL, 2015). Nessa perspectiva, o curso da UFRB inseriu essas temáticas em todos os componentes curriculares dos seus estágios, legitimando assim essa proposição.

Os cursos da UEFS, UFOB/Barreiras e UFRB/Amargosa, com a reformulação para atender a Resolução CNE/CP 02/2015, passaram a colocar em debate, temáticas como: educação inclusiva, interdisciplinaridade e questões diversidades étnico-racial, de gênero e/ou sexual. Entretanto, observamos que todos os cursos operam uma configuração muito próxima da apresentação estrutural das atividades dos componentes curriculares, legitimando a tríade observação, coparticipação e regência, sem um aparente propósito investigativo, o que pode dificultar a produção de novos textos e a recontextualização em outros contextos.

A UFSB traz uma proposta formativa diferente dos demais cursos. Desde o quarto período de curso, o estudante é inserido progressivamente em espaços educacionais formais e não formais, em etapas progressivas com durações flexíveis, sempre articulado aos demais componentes curriculares. A princípio, o estagiário faz observação ativa no espaço educacional e vai progredindo à medida em que o reconhece. Por meio de um sistema integrado de aprendizagem compartilhada, o estagiário conta com o apoio de outros estagiários em etapas mais avançadas, o residente tutorando estagiários nas últimas etapas do estágio; os estagiários nas últimas etapas tutorando estagiários em etapas intermediárias; e os estagiários de etapas intermediárias, tutorando os estagiários em etapas iniciais; em todos os casos, sob a supervisão de um docente-preceptor da Educação Básica e sob a orientação de docente do curso (UFSB, 2016). Esse sistema lembra a experiência de formação médica, onde um preceptor acompanha um residente, ação que contribui para a aproximação entre conhecimentos teóricos e práticos e favorece o acolhimento do estagiário de forma tencionada (GATTI et al., 2019). 
Destaque-se a existência de Complexos Integrados de Educação (CIEs), composto de Centro de Ensino Médio Integral, Centro Noturno de Ensino, Centro de Formação Docente Continuada e Colégio Universitário como espaços em que os estágios podem ser realizados. Esses CIEs objetivam aprimorar o processo de formação de professores da rede pública, promovendo assim a integração do curso superior com a Educação Básica. Neste ponto, é possível observar um encontro entre formação inicial e continuada, proposição encontrada na diretriz de 2015. Observa-se que mesmo tendo 400 horas de carga horária, o estágio da UFSB traz uma proposta de operacionalização distinta dos estágios dos demais cursos, voltado à interdisciplinaridade, trabalho coletivo e ao amadurecimento progressivo do estagiário para a práxis docente. Para Pimenta e Lima (2019), o estágio deve se constituir em eixo central e articulador do curso desde o seu início, com a finalidade de instrumentalizar teoricamente os estudantes estagiários. Assim, acreditamos ser possível um trabalho de articulação e diálogo entre teoria e prática, universidade e escola de Educação Básica, ensino, pesquisa e extensão na construção de uma práxis educativa docente.

Neste sentido, à luz das teorias de Bernstein $(2000,2003)$, argumentamos que quando textos das DCN a respeito do estágio são movidos, por exemplo, pelos membros do colegiado, o discurso pedagógico age em temos da seleção, refocalização ou supressão sobre o que mover e como mover em termos dos princípios que operam na construção/adequações dos PPC de Licenciatura em Matemática. Este processo de deslocamento de textos das DCN para os PPC colidem com princípios desse último e implícita ou explicitamente demarcam relações de poder. A força da classificação é que tende a manter os campos isolados por meio de fronteiras que demarcam o papel de cada um. Por essa razão convidamos os leitores, pensar o estágio como um ato de (re)existir e elaborar propostas que articulem universidade e escola, formação inicial e continuada, ensino, pesquisa e extensão em prol da formação de futuros professores de matemática.

\section{Considerações Finais}

Ao propor analisar como foram recontextualizados os textos das DCN para os PPC de Licenciatura em Matemática em universidades estaduais e federais do estado da Bahia, observamos que eles foram recontextualizados, nos termos postos por Bernstein $(2000,2003)$. Os resultados desta investigação apontam para convergências e divergências na operacionalização dos projetos, o que permite apontar sobre a liberdade de escolha de aspectos subjacentes e formas de organização durante o delineamento das propostas analisadas. Os textos encontrados nas DCN foram realocados e reposicionados de forma seletiva nos PPC, a partir das compreensões e interpretações dos colegiados responsáveis pela sua reformulação. 
Consideramos que o Estágio Curricular Supervisionado desempenha um papel fundamental nos cursos de Licenciatura em Matemática, configurando um espaço privilegiado de integração dos momentos que constituem a formação de professores. E, apesar de ser componente obrigatório, segundo Gatti et al. (2019), historicamente constitui-se um desafio para as instituições de formação e para as escolas da Educação Básica.

Nesse sentido, pudemos observar certa hegemonia na forma como os cursos operam a estrutura das atividades dos componentes curriculares, legitimando a histórica tríade observação, coparticipação e regência, um modelo que limita as possiblidades de vivências nas diferentes etapas e modalidades de ensino, em espaços formais e não formais, durante a realização dos estágios.

Entendendo esse contexto, conseguimos visualizar, na proposta de estágio da UFSB, uma forma de resistência que possibilita desconstruir um modelo de estágio que se solidificou nos processos de formação inicial de professores. Encontramos nesse curso uma proposta de integração contínua entre universidade e escola, formação inicial e continuada, professores da educação básica e professores das licenciaturas, alunos mais experientes com alunos iniciantes, promovendo assim a realização de um trabalho de colaboração e de partilha de aprendizagens. Essa proposta, segundo Gatti et al. (2019), permite a identificação e a análise conjunta de situações, dificuldades e desafios postos para a prática pedagógica na Educação Básica, assim como as possibilidades de superação por meio da produção coletiva de novos fazeres docentes.

Sinalizamos que, no momento de escrita deste artigo, temos como documento normatizador das licenciaturas a Resolução CNE/CP 2/2019 que define as Diretrizes Curriculares Nacionais para a Formação Inicial de Professores para a Educação Básica e institui a Base Nacional Comum para a Formação Inicial de Professores da Educação Básica (BNC-Formação). Por ser recente, não encontramos cursos que tenham reformulado seus projetos para atendê-la. Resumidamente, ela é um documento que resgata a noção de competências como orientadora da formação de professores, motivando uma formação pragmática, direcionada ao domínio de competências e habilidades. Ela reduz a formação às regras da Base Nacional Comum Curricular (BNCC), preparando o futuro professor para a realização de tarefas práticas, consequentemente, centraliza o conhecimento do conteúdo a ser ensinado como essencial para a formação.

Nessa perspectiva, demarcamos nossa preocupação com a possibilidade dos estágios se transformarem em espaço de reprodução, de instrumentalização de técnicas, legitimando a máxima de que estágio é local de fazer aplicação da teoria. Isso o reduziria a uma prática como imitação de modelos, algo a ser esmiuçado por meio da profunda observação, tentando dotar os estagiários de competências e habilidades para o trabalho (PIMENTA; LIMA, 2019). 
Ressaltamos a pertinência de compreender o estágio como um eixo articulador da formação, que oportuniza uma articulação entre as disciplinas e as atividades tradicionalmente denominadas práticas e teóricas do currículo, o diálogo entre universidade e escola, entre formação inicial e continuada. Nesse sentido, os estagiários seriam instrumentalizados não apenas por meio de competências, mas também teoricamente, permitindo análises e problematizações da práxis educativa que ocorrem nas escolas, nas salas de aula, objetivando que em sua atuação eles possam colaborar para as transformações necessárias para assegurar a emancipação humana e social de seus alunos (PIMENTA; LIMA, 2019).

Desse modo, sinalizamos que avançar nos estudos empíricos sobre as propostas de Estágio delineadas nos cursos de licenciatura em Matemática nacional seria útil para identificarmos as limitações e potencialidades dos modelos formativos e suas implicações sobre a formação inicial de professores de Matemática.

\section{Referências}

ADLER, Patrícia. A.; Adler, Peter. Observational techniques. In: DENZIN, Norman. K; LINCOLN, Yvonna. S. Handbook of qualitative research. Thousand Oaks: Sage, 1994.

BARBOSA, Cirléia Pereira; LOPES, Celi Espasandin. Uma análise da produção acadêmica brasileira sobre o Estágio Curricular Supervisionado nos cursos de Licenciatura em Matemática. Revista de Educação Matemática, São Paulo, v. 18, 2021, pp. 1-23 - e021014.

BRASIL. Lei $n^{0}$ 9.394, de 20 de dezembro de 1996. Estabelece as diretrizes e bases da educação nacional. Diário Oficial da União, Brasília, 21 dez. 1996.

BRASIL. Conselho Nacional de Educação. Institui Diretrizes Curriculares Nacionais para a Formação de Professores da Educação Básica, em nível superior, curso de licenciatura, de graduação plena. Resolução CNE/CP n. 01/2002. Diário Oficial da União, Brasília. Seção 1, p. 31, 09 abr. de 2002a.

BRASIL. Conselho Nacional de Educação. Conselho Pleno. Institui a duração e a carga horária dos cursos de licenciatura, de graduação plena de formação de professores da Educação Básica em nível superior. Resolução CNE/CP n. 02/2002. Diário Oficial da União, Brasília. Seção 1, p. 9, 4 mar. de $2002 b$.

BRASIL. Conselho Nacional de Educação. Câmara de Educação Superior. Estabelece as Diretrizes Curriculares para os cursos de Matemática. Resolução CNE/CES 3/2003, de 18 de fevereiro de 2003. Diário Oficial da União, Brasília, Seção 1, p. 13, 25 de fev. de 2003.

BRASIL. Conselho Nacional de Educação. Define as Diretrizes Curriculares Nacionais para a formação inicial em nível superior (cursos de licenciatura, cursos de formação pedagógica para graduados e cursos de segunda licenciatura) e para a formação continuada. Resolução CNE/CP n. 02/2015. Diário Oficial União, Brasília, seção 1, n. 124, p. 8-12, 02 de julho de 2015. 
BRASIL. Resolução CNE/CP n. 02/2019, de 20 de dezembro de 2019. Define as Diretrizes Curriculares Nacionais para a Formação Inicial de Professores para a Educação Básica e institui a Base Nacional Comum para a Formação Inicial de Professores da Educação Básica (BNC-Formação. Diário Oficial da União, Brasília, DF, 20 dez. 2019.

BERNSTEIN, Basil. Class, codes and control: the structuring of pedagogic discourse. Londres: Routledge; Taylor \& Francis Group, 2003.

BERNSTEIN, Basil. Pedagogy, symbolic control and identity: theoryresearch Critique. Revised Edition. London: Taylor and Francis, 2000.

COSTA, Patrícia Santana; SANTANA, Flávia Cristina de Macêdo; LUNA, Ana Virginia de Almeida. Estágio supervisionado curricular em matemática: o sequenciamento e o ritmo em uma oficina sobre estatística. JIEEM, São Paulo, v.13, n.4, p. 472-482, 2020 (Edição especial).

DOURADO, Luiz Fernandes. Formação de Profissionais do Magistério da Educação Básica: novas diretrizes e perspectivas. Comunicação \& Educação, São Paulo, v. 21, n. 1, p. 27-33, 2016.

GABASSA,Vanessa; ELIAS, Carine Rossi; GIROTTO, Vanessa Cristina. O estágio não convencional e suas contribuições à formação docente. EDUCATIVA, Goiânia: PUC GOIÁS v. 20, n. 2, p. 408-430, maio/ago. 2017.

GATTI, Bernardete Angelina; et al. Professores do Brasil: novos cenários de formação. [S.I: s.n.], 2019.

LOPES, Alice Casimiro. Políticas de integração curricular. Rio de Janeiro: EdUERJ, 2008.

LÜDKE, Menga; ANDRÉ, Marli E. D. A. Pesquisa em educação: abordagens qualitativas. São Paulo: EPU, 2005.

MANRIQUE, Ana Lúcia. Licenciatura em matemática: formação para a docência $x$ formação específica. Educ. Matem. Pesq., São Paulo, v.11, n.3, p.515-534, 2009.

NÖRNBERG, Marta; CAVA, Patrícia Pereira. Aprendizagem compartilhada da ação docente. ANPED. 2015. Disponível em: https://anped.org.br/sites/default/files/trabalho-gt08-4274.pdf. Acesso em: 07 de agosto de 2020. In: $37^{a}$ Reunião Nacional da ANPED, Florianópolis. Anais...Florianópolis: Universidade Federal de Santana Catarina (UFSC), 04- 08, out. 2015.

NEVES, Regina da Silva Pina; Fiorentini, Dario. Aprendizagens de Futuros Professores de Matemática em um Estágio Curricular Supervisionado em Processo de Lesson Study. Perspectivas da Educação Matemática, Mato Grosso do Sul, v. 14, n. 34, p. 1-30, 12 abr. 2021.

PIMENTA, Selma Garrido; LIMA, Maria do Socorro Lucena. Estágios supervisionados e o Programa Institucional de Bolsa de Iniciação à Docência: duas faces da mesma moeda? Rev. Bras. Educ. Rio de Janeiro, v. 24, e240001, p. 1-20, 2019. http://www.scielo.br/scielo.php?script=sci_arttext\&pid=\$1413-24782019000100200\&lng=pt\&nrm=iso. Acesso em 07 de agosto de 2020

PIMENTA, Selma Garrido; LIMA, Maria do Socorro Lucena. Os (des) caminhos das políticas de formação de professores - 0 caso dos estágios supervisionados e o Programa de iniciação à docência: duas faces da mesma moeda? In: $38^{a}$ Reunião Científica da ANPED, 38, 2017, São Luis. Anais... São Luis: Universidade Federal do Maranhão (UFMA), 4-8, out. 2017. 
RABELO; Leandro de Oliveira; ABIB, Maria Lucia Vital dos Santos; AZEVEDO, Maria Nizete de Azevedo. Estágio com Pesquisa na Formação Inicial de Professores: transformação dos sentidos sobre a atividade docente. Ciência \& Educação, Bauru, v. 27, e21001, 2021.

RINCÓN, Jenny Patricia Acevedo; FIORENTINI, Dario. Práticas na formação dos licenciados em matemáticas: a experiência de una prática interdisciplinar. Rev. Fac. Cienc. Tecnol. n.40 Bogotá July/Dec. 2016.

SANTANA, Flávia Cristina de Macêdo; BARBOSA, Jonei Cerqueira. As relações Pedagógicas em um trabalho colaborativo envolvendo Professores de matemática: do conflito à gestão. IN: CYRINO, Márcia Cyrino de Costa Trindade. Temáticas Emergentes de Pesquisas sobre a Formação de Professores que Ensinam Matemática: Desafios e Perspectivas. Brasília: SBEM, 2018. (Coleção SBEM; 10).

SILVA, Ulisses Dias da; OLIVEIRA, Ana Teresa de Carvalho Correa de. Influências do Estágio Supervisionado para Professores de Matemática em Início de Carreira - buscando compreender escolhas e características das escolas-campo. Revista Baiana de Educação Matemática, Juazeiro, v. 2, n. 1, p. 01-25, e202101, p. 1-25, jan./dez., 2021.

TEIXEIRA, Bruno Rodrigo; CYRINO, Márcia. Cyrino. de Costa. Trindade. O Estágio de Regência como Contexto para o Desenvolvimento da Identidade Profissional Docente de Futuros Professores de Matemática. ALEXANDRIA, Santa Catarina: UFSC, v.8, n.3, p.131-149, nov. 2015.

UEFS. Projeto Pedagógico do Curso de Licenciatura em Matemática. Feira de Santana: Universidade Estadual de Feira de Santana, 2018.

UESB. Projeto Pedagógico do Curso de Licenciatura em Matemática com Enfoque em Informática. Jequié: Universidade Estadual do Sudoeste da Bahia, 2011.

UESB. Renovação de Reconhecimento do Curso de Licenciatura em Matemática. Vitória da Conquista: Universidade Estadual do Sudoeste da Bahia, 2010.

UESC. Projeto Acadêmico Curricular Curso de Licenciatura em Matemática. Ilhéus: Universidade Estadual de Santa Cruz, 2006.

UFBA. Projeto Pedagógico do Curso Noturno de Licenciatura em Matemática. Salvador: Universidade Federal da Bahia, 2008.

UFOB. Projeto Pedagógico do Curso de Licenciatura em Matemática. Barreiras: Universidade Federal do Oeste da Bahia, 2016.

UFRB. Projeto Pedagógico do Curso de Licenciatura em Matemática. Cruz das Almas: Universidade Federal do Recôncavo da Bahia, 2018.

UFSB. Projeto Pedagógico de Curso Licenciatura Interdisciplinar em Matemática e Computação e suas Tecnologias. Itabuna / Porto Seguro / Teixeira de Freitas: Universidade Federal do Sul da Bahia, 2016.

UNEB. Projeto de Reconhecimento do Curso de Licenciatura em Matemática. Alagoinhas: Universidade do Estado da Bahia, 2011.

UNEB. Projeto de Reconhecimento do Curso de Licenciatura em Matemática. Barreiras: Universidade do Estado da Bahia, 2011. 


\section{revemop}

UNEB. Projeto de Reconhecimento do Curso de Licenciatura em Matemática. Senhor do Bonfim: Universidade do Estado da Bahia, 2011.

UNEB. Projeto de Reconhecimento do Curso de Licenciatura em Matemática. Teixeira de Freitas: Universidade do Estado da Bahia, 2012.

UNEB. Projeto de Reconhecimento do Curso de Licenciatura em Matemática. Paulo Afonso: Universidade do Estado da Bahia, 2012.

UNEB. Projeto do Curso de Licenciatura em Matemática Para Fins de Reconhecimento. Caetité: Universidade do Estado da Bahia, 2010. 